\title{
Self-Verification: Application in Organizational Management
}

\author{
Lihu Sun ${ }^{1}$ Yarong Zhang,** \\ ${ }^{1}$ School of Business Administration, Shanxi University of Finance and Economics, Taiyuan, China \\ ${ }^{2}$ School of Business Administration, Shanxi University of Finance and Economics, Taiyuan, China \\ ${ }^{*}$ Corresponding author. Email: 2447646586@qq.com
}

\begin{abstract}
People always have the psychology and behavior to seek, maintain and strengthen themselves. Once individuals have ideas about themselves, they will try to prove these self-concepts. Self-verification theory believes that individuals have a tendency to understand their true self. Based on the review of the existing research on self-verification theory, the article outlines the connotation of self-verification, the difference and comparison of similar concepts, influencing factors and the objects of occurrence, and focuses on the field of organizational behavior to sort out the theory' s role in organizational management. Application, and finally form the research framework of integrated self-verification theory in the field of organizational behavior.
\end{abstract}

Keywords: Self-verification1, Self-concept2, Organization management3

\section{INTRODUCTION}

The logical connotation of self-verification theory first appeared in the study of symbolic interaction theory. Symbolic interaction theory mainly studies the process of human interaction based on meaningful symbols, and meaning does not come from things themselves.But from the interaction with others, that is, the individual judges himself through others [1]. With Swann' s systematic research and analysis of self-verification, more scholars have conducted in-depth research on self-verification in various fields. So far, domestic and foreign research on self-verification involves social psychology, psychotherapy, education and developmental psychology. There are many aspects of organization management and consumption. However, there is only one general article on self-verification in China. Gu Meixi [2] only summarizes its applied research in the fields of social psychology, psychotherapy, educational psychology, etc. Although self-verification theory is derived from social psychology, it has been increasingly used to explain organizational phenomena in recent years (in the search of CNKI, self-verification research has been increasingly applied in organizational management, the proportion is getting heavier), which has an important impact on management research.Therefore, it is necessary to systematically sort out the current research status of self-verification in organizational management, and propose new research directions in the future, followed by existing the theoretical foundation is also rather chaotic and fragmented. In view of this, this article uses "self-verification", "self-concept", "selfenhancement", "self-verification" and "self-motivation" as search terms in Chinese and English databases such as Google Scholar, Springre Link, Wanfang Database, and CNKI. After searching and reading them one by one, 30 relevant documents were finally sorted out as the main research objects of this article. Through a review of related literature, this article focuses on sorting out selfverification from three aspects: first, it sorts out the connotation of self-verification and the comparison of similar concepts; secondly, it summarizes the current application of self-verification in organizational management; based on the literature review, an integrated self-verification research framework in organizational management is formed.

\section{THE CONNOTATION OF SELF- VERIFICATION}

\subsection{The concept of self-verification theory}

Mead first proposed the logical connotation of the self-verification theory, and later Lecky proposed the core idea of the self-verification theory, which holds that individuals have a strong sense of agreement on the basis 
of long-term self-identity, and there will be behaviors that maintain this sense of coherence. Based on previous research, William B. Swann proposed the selfverification theory in the 1980s. This theory advocates that once an individual has the idea of seeking consistency between self-perception and the information to be obtained, he will constantly seek or elicit feedback consistent with its self-concept [3], that is, people will continue to work hard to verify themselves in order to better maintain and strengthen their original self-concept. With the development of self-verification in more different fields, its definition is also different, as shown in Table 1.

Table 1. The development of self-verification in different fields.

\begin{tabular}{|c|c|c|}
\hline Presenter & Perspective & Definition \\
\hline $\begin{array}{l}\text { Mead } \\
(1934)\end{array}$ & $\begin{array}{l}\text { Social } \\
\text { Interaction }\end{array}$ & $\begin{array}{l}\text { It is emphasized that individuals } \\
\text { make inferences about } \\
\text { themselves through others' views } \\
\text { of themselves, and finally form a } \\
\text { stable view of themselves. }\end{array}$ \\
\hline $\begin{array}{l}\text { Lecky } \\
\text { (1945) }\end{array}$ & $\begin{array}{l}\text { Consumer } \\
\text { Behavior } \\
\text { (Psychology) }\end{array}$ & $\begin{array}{l}\text { It is believed that the relatively } \\
\text { stable self-view formed by the } \\
\text { individual over a long period of } \\
\text { time will stimulate the inner sense } \\
\text { of consistency, and then the } \\
\text { individual will take action in to } \\
\text { maintain this sense of consistency. }\end{array}$ \\
\hline $\begin{array}{l}\text { Meng } \\
\text { Nan,et al. } \\
(2017)\end{array}$ & $\begin{array}{l}\text { Social } \\
\text { Psychology }\end{array}$ & $\begin{array}{l}\text { The individual edits the selfie in } \\
\text { order to verify and strengthen the } \\
\text { original self-concept. When the } \\
\text { individual's original self-concept is } \\
\text { affirmed, they will gain a sense of } \\
\text { control and certainty about the } \\
\text { outside world, which in turn affects } \\
\text { subjective well-being. }\end{array}$ \\
\hline $\begin{array}{l}\text { Yue Tong } \\
(2012) \\
\text { Deng } \\
\text { Haixiong } \\
(2019)\end{array}$ & Team & $\begin{array}{l}\text { It is believed that individuals will try } \\
\text { to seek consistency between self- } \\
\text { awareness and between self- } \\
\text { awareness and the information to } \\
\text { be obtained. } \\
\text { People not only want others to } \\
\text { affirm themselves, but also want } \\
\text { others' self-assessment. }\end{array}$ \\
\hline $\begin{array}{l}\text { Xu Jingxing } \\
(2015)\end{array}$ & $\begin{array}{l}\text { Development } \\
\text { Education }\end{array}$ & $\begin{array}{l}\text { In order to verify self-verification, } \\
\text { individuals hope that others can } \\
\text { affirm themselves, and that others' } \\
\text { affirmation of their own } \\
\text { advantages and disadvantages is } \\
\text { more useful than positive } \\
\text { evaluation. }\end{array}$ \\
\hline
\end{tabular}

Source: Organized according to relevant literature.

\subsection{Differences in related concepts}

Different psychologists have put forward various self-motivation theories, including self-enhancement, self-evaluation, self-improvement and self-verification. The argument between self-verification and these three types of self-motivation is very fierce, so it is necessary to argue and coordinate them in order to better use them.

\subsubsection{Self-Verification and Self-Enhancement}

The self-enhancement theory believes that people will prefer to be positively evaluated from others in order to improve their value [8]. Self-enhancement is both a motivation for self-enhancement, that is, people will quickly respond to positive information related to self; it is also a self-enhancement bias, that is, the behavioral bias of people in the search for a better self in research. In the core view of self-enhancement theory, the improvement of personal sense of value and maintaining self-esteem are the needs of everyone.

Both self-verification and self-enhancement believe that people with positive self-views will maintain their positive views and seek positive feedback, but the two theories are different in the explanation of the cause. Swann et al. [3] found that in the experiment of selecting communication partners: whether they are people with high self-esteem or people with low self-esteem, selfenhancement is manifested in that they prefer contact partners who can provide positive self-feature feedback, while self-verification is expressed as Prefer partners who can provide negative feedback (As shown in Table 2).

Table 2. Differences between self-verification and selfenhancement.

\begin{tabular}{c|c|c}
\hline Dimension & Self-verification & Self-enhancement \\
\hline Behavior & Behind the behavior & $\begin{array}{c}\text { In the course of } \\
\text { behavior }\end{array}$ \\
\hline Positive personality & $\begin{array}{c}\text { Seek positive } \\
\text { feedback }\end{array}$ & $\begin{array}{c}\text { Seek positive } \\
\text { feedback }\end{array}$ \\
\hline Negative personality & $\begin{array}{c}\text { Inclined to negative } \\
\text { feedback }\end{array}$ & $\begin{array}{c}\text { Still seek positive } \\
\text { feedback }\end{array}$ \\
\hline
\end{tabular}

Source: Organized according to relevant literature.

\subsubsection{Self-Verification and Self-Assessment}

The self-assessment theory believes that people have the urge to understand their true self. In order to make individuals more certain about their abilities and personality characteristics, they will collect effective information to judge through various channels [2]. Swann believes that the motivation for self-verification comes from self-assessment. In the process of seeking the true self, self-verification and self-assessment are complementary, but the two theories are different in information preference. The former prefer to receive selfdetermined information, while the latter tend to receive accurate and objective evaluations of the uncertain self (As shown in Figure 1).

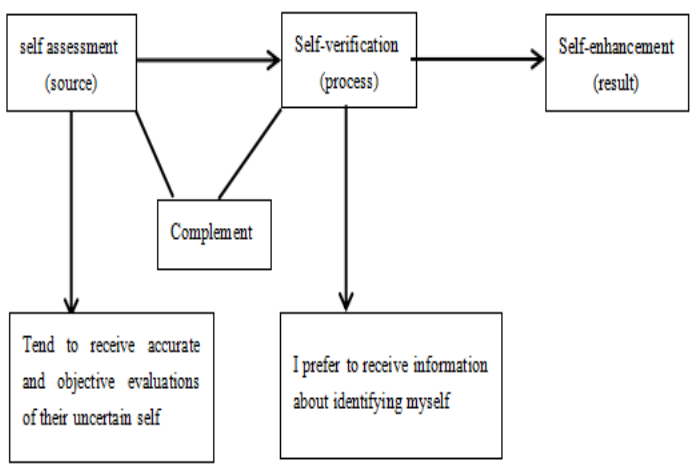

Figure 1 Self-relationship icon 


\subsubsection{Self-Verification and Self-Improvement}

Self-improvement, or self-glorification, is an important motivation for keeping oneself feeling good. It refers to the way individuals choose to benefit themselves when collecting and interpreting information about themselves. Self-improvement and self-verification predict the same for individuals with positive selfawareness, and both believe that they will actively seek positive evaluations [5], but predictions for negative individuals indicate that self-improvement individuals will seek positive feedback and the self-verified individuals will accept negative information (As shown in Table 3). Kwang and Swann [10] based on the metaanalysis of related research that the two motivations are dominant at different stages of the individual selfevaluation process, and the self-verification effect is dominant in the partial cognitive response to the self , self-improvement motivation has an advantage in the response to emotional information [1] and if the risk of rejection in interaction with others is higher, selfimprovement motivation is stronger than self-verification motivation. In short, research on the specific situations and elements generated by the two motivations shows that self-improvement and self-verification motivations are not completely unrelated, but are self-motivations that exist at the same time but are selectively activated due to differences in specific situations [1].

Table 3. The difference between self-verification and self-improvement

\begin{tabular}{l|l|l}
\hline Dimension & Self-verification & Self-improvement \\
\hline Positive personality & $\begin{array}{l}\text { Actively seek } \\
\text { Positive evaluation }\end{array}$ & $\begin{array}{l}\text { Actively seek } \\
\text { Positive evaluation }\end{array}$ \\
\hline Negative personality & $\begin{array}{l}\text { Tend to accept } \\
\text { negative } \\
\text { information }\end{array}$ & $\begin{array}{l}\text { Still seeking } \\
\text { positive feedback }\end{array}$ \\
\hline
\end{tabular}

Source: Organized according to relevant literature.

\section{THE REASON AND PROCESS OF SELF- VERIFICATION}

\subsection{Reasons for self-verification}

Lecky proposed that once the self-view is developed, it will give people a strong sense of coherence. In order to maintain this sense of coherence, people are committed to stabilizing and maintaining the self-view. Self-verifiers are not to change their opinions, but to match their behavior, but to maximize the extent to which their experience confirms and strengthens their relatively persistent self-view.

Self-verification theory believes that a stable selfview provides people with an important source of continuity and continuity, and is an important means to define their existence, organize experience, predict future events, and guide social interactions. In addition, through stable behavior, a stable self-view makes people more predictable about others. This in turn increases predictability, which stabilizes the way others react. In this way, a stable self-view forms a coherent social environment, which further stabilizes people's self-view. The fundamental reason for individual self-verification is that it has the motivation to enhance the prediction and control of reality (see Figure 2). Self-verification enhances people' $\mathrm{s}$ perception of prediction and control in two ways:

(1) In terms of cognition, self-verification helps to form a stable self-concept, enhances confidence, helps to better understand the world, and enhances their psychological coherence;

(2) In practical terms, self-verification drives individuals to seek external evaluation consistent with their self-concepts, thereby strengthening the role of selfrecognized identity, making social interactions predictable and manageable, and ensuring their interactions proceed smoothly.

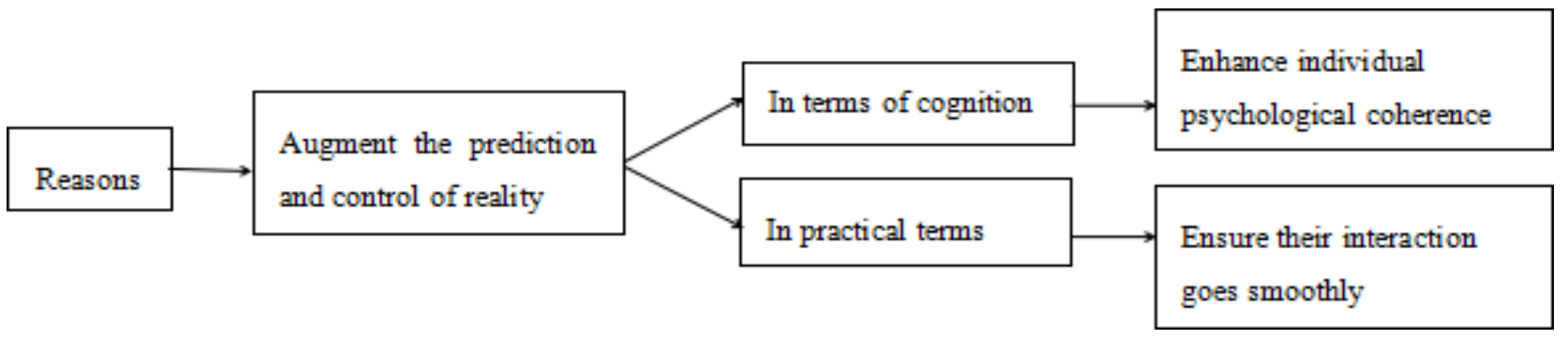

Figure 2 Reasons for self-verification

For these two reasons, if people perceive themselves in a self-congruent manner, they can enhance the security of existence and calm the waters of social interaction; if they perceive themselves in a self-congruent manner, may produce the equivalent of epistemology and practicality like tidal waves. People try to avoid such disasters by entering and creating a social world that can prove their self-view.

\subsection{The process of self-verification Reasons for self-verification}

Swann, Rentfrow, and Guinn [11] use the model of "selection-interpretation-retention" to explain the process of people seeking self-verification. People mainly verify themselves through two ways to create a social 
environment for verifying self and subjective distortion of reality information. In terms of creating a self-verified social environment, there are three specific aspects: choosing a communication partner and environment; intentionally displaying identity cues; and adopting a communication strategy that can trigger self-verification feedback. People often seek to establish relationships that are consistent with their self-concepts, and to break away from relationships that cannot obtain self-verification [12], to convey "hint" that conforms to their identity and guide others to make evaluations of self-cognition verification [13] and other ways to intentionally or unintentionally build a social environment that can prove self-concept [14]. The subjective distortion of real information also includes three aspects: selective attention; selective encoding and extraction; and selective interpretation [15]. The above self-verification methods are summarized by Swann on the basis of a large number of previous studies, which are supported by a large number of empirical studies [9] .

In different groups, the self-verification process is particularly beneficial. Members of different groups are usually very careful not to express controversial ideas because they are worried that they will be misunderstood. Self-verification can be reduced by making these people believe that they are understood. This worry, therefore, they may open up to colleagues, which in turn will lead them to express some alternative ideas, so as to solve the problem creatively, and the performance may benefit accordingly. Similarly, the self-verification process may help eliminate social stereotypes. In a small group, when the target object asks the perceive for self-verification, the perceive will be more inclined to individualize the target object - that is, admit that they are Unique individuals, not typical of social stereotypes. Over time, individualization can be beneficial to both the target and the perceive. The reason why the target is benefited is that being treated as a unique individual will increase they develop the possibility of qualities that reflect their peculiar competence and strength; at the same time, the perceive benefits, because recognizing the unique qualities of the target will encourage them to avoid applying false social stereotypes.

\section{APPLICATION OF SELF- VERIFICATION IN ORGANIZATION MANAGEMENT}

So far, self-verification has a wide range of applications. Foreign research on self-verification involves social psychology, psychotherapy, developmental and educational psychology, team management and consumption, etc. The objects involved include youth, couples, students, depression patients, and Workplace employees, etc. Compared with foreign countries, China's research on self-verification involves fewer fields. The existing empirical studies are mainly the research on self-verification on employees suggestions in organizational management [5], selfverification The impact of verification on workplace rejection [16], the impact of self-verification in social psychology [4], research on self-verification and persuasion [17], self-verification and negativity research on self-conceptists [5], etc. Empirical research shows that self-verification has a positive impact on team performance, such as team interpersonal relationships and performance, group identity, and team creativity; selfverification can also predict individual-level performance, including work performance and employee behavior, positive emotions, and trust and commitment. This article focuses on the research status of selfverification theory in organizational management, and makes an integrated framework diagram of the antecedents, results, intermediaries, and moderating variables studied so far (see Figure 3), specifically: 


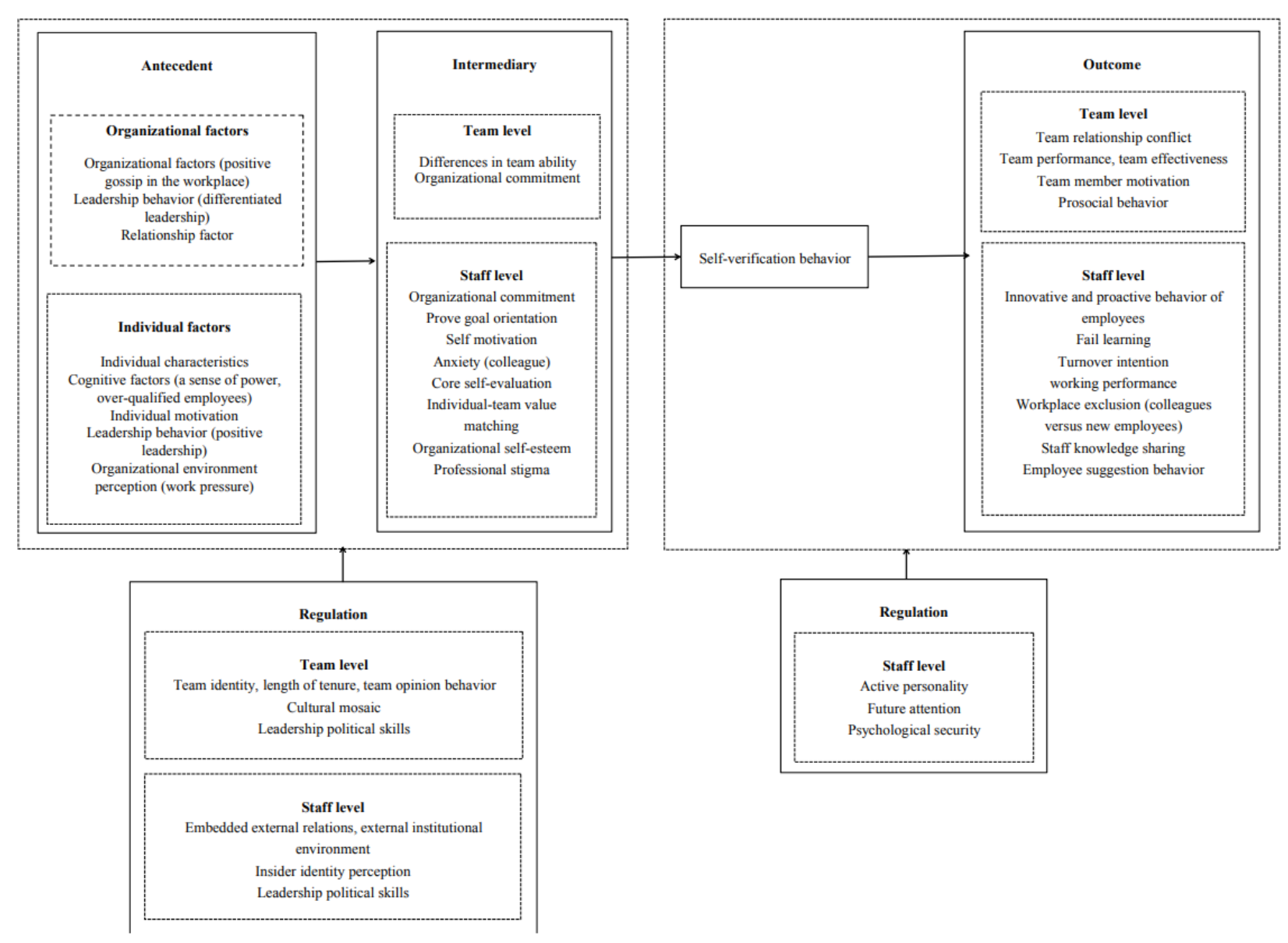

Figure 3 Application framework diagram of self-verification theory in the field of organizational behavior

\subsection{Antecedent Research}

The fundamental reason for individual selfverification is that it has the motivation to enhance the prediction and control of reality. The individual's selfverification is not permanent, but as the environment becomes uncertain, the individual will have a new selfdoubt and start a new round of self-verification behavior. In an organization, in order to pursue a sense of wholeness, individuals will strive to seek consistency between self and external information. When receiving information, individuals will verify themselves [6], and will produce verification when they feel different leadership atmospheres [18], self-verification occurs when feeling pressure [19], and self-verification when feeling different from others [16]. The changes of these organizational factors and the role of personal factors will generate a motivation for individuals to verify themselves.

\subsection{Outcome Research}

\subsubsection{Team level}

Through relevant research and analysis, individuals in a complex and diverse team have a higher pursuit of self-verification and evaluation. From the perspective of the individual, people will always actively obtain selfverification information from others; while standing in the team from the perspective of members, the evaluation of the target individual to verify their self-perception is a kind of respect and tolerance based on understanding others.

In the early years, when scholars such as Swann [20], studied the role of self-verification in a team, they found that a high degree of self-verification can improve team performance and stimulate team members. In the study of team interpersonal consistency, Han Lifeng et al. [19] found that self-verification can promote interpersonal consistency, enhance the emotional connection of individuals to the group, and ultimately enhance team effectiveness. In recent years, in research on team conflicts, Erica Xu [21], Li Shaolong [18] and other scholars found that accepting self-verification can smooth interpersonal interaction, and self-verification can enhance the sense of connection between group members and even reduce relationship conflict. Even in a multicultural team, this conclusion is still valid [22]. 


\subsubsection{Staff level}

\subsubsection{Staff turnover tendency}

Individuals with negative self-views seek negative feedback to ensure a sense of personal constancy. They are often negatively faced with family, workplace, and organizations, and tend to be psychologically suspicious of themselves, and their tendency to leave is relatively high. Scholars such as Swann studied the effect of employee self-verification on turnover intention and found that people with negative self-views prefer the environment in which they feel rejected. Compared with employees with higher positive self-evaluation, positive self-evaluation is more low employees are more likely to leave after a raise. Amanda [23] also found that loweducated employees' perception of low professional stigma does not provide them with information to control their low self-view. This minimal feedback limits their sense of stability and security, and increases their willingness to leave. Deng Haixiong [6] found in the theoretical study of work pressure on turnover intention that in organizations, individuals will try to verify themselves in order to maintain the consistency between self and external information. If they do not verify, they will doubt themselves, and then produce under various pressures, there is a higher tendency to leave.

\subsubsection{The influence mechanism of workplace exclusion}

Through relevant research and analysis, the role of employee self-verification in workplace exclusion has different effects due to different research objects and environments.

Based on the self-verification theory, domestic studies have confirmed that there is a significant negative correlation between the two. In a related study by Liu Xiaoyu et al. [16], it was found that when an employee is rejected, he will doubt his own ability and value, and make various denials of himself, which ultimately reduces the employee' s organizational self-esteem. Ma Xiaoting studied the positive workplace gossip of new employees on the workplace rejection of colleagues and found that the positive workplace gossip of new employees has a positive effect on colleagues' anxiety, and anxiety has a positive effect on workplace rejection and self-improvement. Wang Qingjin et al. [27] studied the impact of workplace exclusion on employee innovation behavior and found that if employees feel exclusion in the organization, it will have a negative impact on innovation behavior.

Foreign studies have confirmed that there is a significant positive correlation between the two. Scholars such as Swann found in related research that in order to verify their self-view as group members, excluded individuals may engage in compensatory group behaviors, such as increasing help behaviors and reducing social idleness, so as to allow others See and acknowledge that they are members of the group to support their identity within the group. Later, Erica Xu et al. [21] found in their research that when the identity of the group is threatened by exclusion, people will restore their groupbased self-view by engaging in pro-social behaviors rather than "tit for tat" anti-social behavior.

\subsubsection{Work performance}

A large number of studies have shown that selfverification plays a positive role in the study of job performance. In the early days of Swann [28] when studying the role of self-verification in teamwork, he found that a high degree of verification indicates that group heterogeneity can improve team performance. Yang Chen et al. [24] used self-determination theory to construct a theoretical framework in the research on how humble leadership can improve employee performance, and obtained the effectiveness of humble leadership behavior on employee performance. Based on this theory, Hou Xuanfang et al. [29] found that the new generation of work values has a positive effect on performance within and outside roles. Wang Hongyu et al. [30] found that in order to verify their own qualification judgments, individuals with excess qualifications will use job remodeling and career exploration to engage in deviant innovations that meet their own interests and expectations to distinguish their own qualification levels in the research on the sense of excess qualifications and deviant innovation behaviors. Behaviour in order to achieve outside-the-role innovation performance and bring huge innovation benefits to individual and organizational innovation.

\subsubsection{Staff suggestion behavior}

There are few literatures on self-verification and employee suggestion behavior research at home and abroad. Compared with other employees, employees with positive personality will be more proactive in seeking self-knowledge and evaluation. Rong Yan [25] found that the sense of power comes from the individual' $\mathrm{s}$ perception of the organization' $\mathrm{s}$ experience and therefore affects the employee' $s$ organizational selfesteem. The sense of power can improve employee' s organizational self-esteem to improve employees, suggestions behavior. Luo Xingpeng [26], based on the self-verification theory, found that personalorganizational fit is positively correlated with employees , self-verification cognition in a study on the crosslevel impact of positive leadership on employee' $s$ suggestive behavior. Those employees who perceive PG value matching have more high initiative and voluntary motivation to help the organization improve or correct mistakes, so as to make suggestions. 


\subsection{Intermediary Research}

\subsubsection{Team level}

Based on self-verification theory, Li Shaolong et al. [18] explored whether, how and when differentiated leadership has a curve effect on interpersonal conflict within a team, and found that differentiated empowered leadership has no direct curve effect on relationship conflict, but the difference in team ability can ease the curve relationship between differentiated empowered leadership and relationship conflict. Specifically, the view of self-competence is very important to employees. Accepting self-verification can enhance interpersonal communication and relieve social pressure, and differentiated authorized leadership can be regarded as an important sign for team members to verify their own abilities. Differential authorization within a reasonable range can increase team members' self-verification, enhance team members self-identity, and enhance interpersonal relationships,reduce conflicts.

\subsubsection{Staff level}

Amanda et al. [23] found that there is a negative correlation between professional stigma awareness and professional identity and job meaning in a study on service employees and self-verification. Later, some scholars studied the impact of new employees' positive workplace gossip on colleagues' anxiety and found that anxiety played a mediating role in the relationship between positive workplace gossip on workplace rejection and self-improvement. Wang Hongyu [30], based on the theory of self-verification, explored the effect of excess qualifications on employees' deviant innovation, and found that the goal-oriented approach played an intermediary role in the effect of excess qualifications on deviant innovation.

\subsection{Regulation Research}

\subsubsection{Team level}

Based on self-verification theory, Pylin [22] conceptualized cultural embedded beliefs as a psychological atmosphere. Each group member will perceive this atmosphere to promote cognition, acceptance and expression, use cultural diversity in work, and discover culture embedded beliefs can alleviate conflicts, thereby positively regulating performance. In the study of workplace exclusion promoting pro-social responses (ie helping behaviors) and preventing antisocial behaviors, Erica $\mathrm{Xu}$ [21] found that group identity and the tenure of excluded employees act as the moderating effect of common boundary conditions, and positively regulate exclusion and pro-social behavior. The relationship between social behavior.

\subsubsection{Staff level}

In the early days, in the research on the impact of new employees' positive workplace gossip on colleagues' anxiety, it was found that the perception of insider identity positively adjusted the impact of new employees' positive workplace gossip on colleagues' anxiety. Later, Wang Hongyu [30] explored the effect of overqualification on employees' deviant innovation based on the theory of self-verification, and found that future attention positively adjusted the relationship between proving goal-oriented and deviant innovation, and at the same time positively adjusted the role of proving goaloriented. The mediating role between the sense of overqualification and deviant innovation.

\section{CONCLUSION AND OUTLOOK}

\subsection{Conclusion}

This article focuses on self-verification, and summarizes its conceptual connotation, its causes and processes, and its application in the field of organization management, in order to provide enlightenment for future empirical research in organization management and expansion in new fields. Specifically, this research has the following conclusions: first, although the definition of self-verification is different in different fields and from different perspectives in the same field, the connotation expressed is the same, that is, the individual has understanding the tendency of true self; secondly, the motivation of self-verification comes from selfassessment, and these two motives are complementary, and finally manifested through self-enhancement. However, there are more researches on self-enhancement, and self-verification research is relatively very few, so this article argues and coordinates them, distinguishes their similarities and differences, so that they can be used more accurately in future research; third, in recent years, self-verification has been increasingly used to explain organizational phenomena, and to the research has had an important impact, but there is no article to sort out its research status in organization and management. This article sorts out its research in organization and management and forms a framework.

\subsection{Outlook}

Although the theory of self-verification originated from social psychology, it has been increasingly used to explain organizational phenomena in recent years, and has had an important impact on management research. By systematically combing and integrating relevant research results, it has been found that self-verification is still a huge space for research in organizational management, and future research content can be further explored from the following aspects. 
First, the influencing factors. At present, the research on the influencing factors of the self-verification theoretical framework is still in the exploratory stage, and there are not many empirical studies. Among them, there are many individual factors, but the organizational factors are relatively scarce. Future research can dig deeper into the special role of individual characteristics in teams and organizational contexts. On the other hand, grounded research methods can be used to explore the differences between individual factors and organizational factors caused by cultural differences in the Chinese context.

Second, cross-level research. At present, the research on self-verification in team research only studies one factor of the team, and the theory of self-verification is currently rarely used in cross-level research. Therefore, in the future, we can consider combining organizational, team, and individual research. Analyze through crosslayer research.

Third, collaborative research on multiple selfmotivations. Among the three main self-motivations, there are many researches on self-enhancement, but the research on self-enhancement and self-verification is relatively insufficient. For example, the current research on the impact of workplace exclusion on employee attitudes and employee behaviors is mainly discussed from the perspectives of social exchange theory and social identity theory, and is less based on selfverification theory, using employees' self-verification motivation as a clue to find that workplace rejection has an effect on employee innovation behavior Negative research not only expands the scope of application of self-verification theory, but also provides new and valuable evidence for the role of the theory in the field of employee innovation behavior. But other possible motives, such as self-improvement motives, are ignored. This article sorts out the disputes and coordination between different motives. Then, in the future research, should we consider multiple self-motivations to explore which motive is at play.

Finally, the theoretical path of constructive deviance. The marginal contribution to self-verification theory from the perspective of over-qualification broadens the research field of self-verification theory, and provides a constructive and deviant theoretical path for follow-up researchers to discuss the self-verification and selfrealization of over-qualified employees. However, the research based on the theoretical perspective of selfverification only explores the sense of over-qualification that brings out-of-role innovation to individuals. In the future, we can explore more changes in employee behavior from this new path. Yang Chen et al. [24] used self-determination theory to construct a theoretical framework for the research on how humble leaders can improve employee performance, and obtained the effect of humble leadership behavior on employee performance, but ignored self-verification and social recognition. Knowing the interaction of theories, the research conclusions have yet to be verified. In the future, the research on how the new type of leadership can improve employee performance under the selfverification perspective is worthy of our in-depth study.

\section{AUTHORS' CONTRIBUTIONS}

Conceptualization, L.S.and Y.Z.; methodology,L.S.; writing - original draft preparation, L.S.; writing review and editing,L.S. and Y.Z.; funding acquisition, L.S. All authors have read and agreed to the published version of the manuscript.

\section{ACKNOWLEDGMENTS}

This paper from the selected topic to finish, every step is done under the guidance of tutor, pour into the teacher a lot of effort. Here, wish to tutor said high respect and heartfelt thanks! In the process of writing papers, met a lot of problems, in under the guidance of the teacher's patience, problems are solved. So, once again to the teacher say: teacher, thank you.

\section{REFERENCES}

[1] Fu Caihong, Lu Houchao. Self-improvement or self-verification:conditions and effects,in: Advances in Psychology, 2013,pp. 9-15.

[2] Gu Meixi,Introduction to Swann's Self-Verification Theory and Empirical Research,in:Psychological Science,2004,pp.

423-428. DOI:CNKI:SUN:XLXD.0.2004-03-013.

[3] W. B.Swann,B .W.Pelham \& D.S.Krull, Agreeable fancy or disagreeable truth? Reconciling selfenhancement and self-verification,in:Journal of personality and social psychology,1989, DOI:

[4] Meng Nan, Wang Yuhui \& Lei Li, The relationship between selfie editors and female college students' subjective well-being: the mediating role of positive feedback and self-concept,in : Psychological Development and Education, 2017, pp.751-758. DOI:10.16187/ j.cnki.issn1001-4918.2017.06.14.

[5] Yue Tong, Wang Xiaogang \& Huang Xiting,Selfstigma of mental illness: a high-risk factor for psychological rehabilitation,in:Advances in Psychological Science,2012,pp.1448-1456. DOI:CNKI:SUN:XLXD.0.2012-09-016.

[6] Deng Haixiong,Theoretical study of self-motivated work pressure on turnover intention,in:Business News, 2019,pp. 184-185. DOI:CNKI:SUN:SYJW.0.2019-16-109. 
[7] Xu Jingxing,An Empirical Study on the Cognitive and Emotional Responses of Junior High School Students under the Motivation of Academic Selfimprovement and Self-Verification,in:Moral Education in Primary and Secondary Schools 2015,pp. 49-52. DOI:CNKI:SUN:XXDY.0.2015-03-018.

[8] Li Yanmei, Fu Jianbin,Self-enhancement and selfverification,in:Psychological

Developments, 1996,pp.24-29.

DOI:CNKI:SUN:XLXD.0.1996-03-005.

[9] T.English, S.Chen, \& W. B.Swann, A cross-cultural analysis of self-verification motives,in $\mathrm{R}$. Sorrentino, \& S. Yamaguchi (Eds.), Handbook of Motivation and Cognition across Cultures ,2008,pp. 119-142. San Diego: Elsevier.

[10] T.Kwang,W. B.Swann,Do People Embrace Praise Even When They Feel Unworthy? A Review of Critical Tests of Self-Enhancement Versus SelfVerification,in:Personality and Social Psychology Review,2010,pp.263-280. DOI:10.1177/1088868310365876.

[11] W. B.Swann, Self-verification theory, In P. Van Lang, A. Kruglanski, \& E. T. Higgins (Eds.), Handbook of Theories of Social Psychology,2002,London: Sage.

[12] A. D. Cast \& P. J. Burke,A Theory of Self-Esteem. Social Forces,2002,pp.1041-1068. DOI:.

[13] S. D.Gosling ,S. J.Ko,T.Mannarelli \& M. E.Morris ,A room with a cue: Personality judgments based on offices and bedrooms,in:Journal of Personality and Social Psychology,2002,pp.379398. DOI:10.1037/0022-3514.82.3.379.

[14] C.Chang-Schneider \& Swann, Wearing selfesteem like a flag: Conveying our high- and lowself-esteem to others, in Press, 2009,University of Texas at Austin.

[15] W. B.Swann\& S. J.Read ,Self-verification processes: How we sustain our selfconceptions,in:Journal of Experimental Social Psychology,1981,pp.351-372.

DOI:10.1016/0022-1031(81)90043-3.

[16] Liu Xiaoyu, Liu Jun, Xu Jun \& Wu Rongrong, The influence mechanism of workplace exclusion on employees' proactive behavior - - Based on the perspective of self-verification theory,in:Psychological Bulletin,2015,pp. 826-836. DOI:CNKI:SUN:XLXB .0.2015-06-012.

[17] Zhou Shengui \& Tang Yonglong,New progress in persuasion research: self-verification
hypothesis.,in:Chongqing and the world,2010,pp. 124-126. DOI:CNKI:SUN:CQSJ.0.2010-11-038.

[18] Li Shaolong,Liao Shudi,Sun Fang \& Guo Zhiwen,Does Differentiated Leadership Threaten Who I Am? Introducing a Self-Verification Perspective to Explain the Curvilinear Effect of Differentiated Empowering Leadership,in:Frontiers in DOI:10.3389/fpsyg.2019.01903 psychology,2019,pp.

[19] Han Lifeng \& Wang Chongming,Self-Verification and Interpersonal Consistency: A New Perspective on the Use of Team Diversity,in:Advances in Psychological Science,2011,pp.73-84 DOI:CNKI:SUN:XLXD.0.2011-01-010.

[20] W.B.Swann,Self-verification: Bring social reality into harmony with the self ,in J. Suls \& A. G. Greenwald (Eds.), Social psychological perspectives on the self,1983,pp.33-66.

[21] Erica Xu,Xu Huang \& L.R.Sandra ,When SelfView Is at Stake: Responses to Ostracism Through the Lens of Self-Verification Theory,in:Journal of Management,2017,pp.2281-2302.

DOI:10.1177/0149206314567779.

[22] Pylin Chuapetcharasopon,Lukas Neville,Wendi L Adair\& Aimy A Racine,Cultural mosaic beliefs as a new measure of the psychological climate for diversity : Individual distinctiveness and synergy in culturally diverse teams,in:International Journal of Cross Cultural Management,2018,pp.7-32. DOI:10.1177/1470595817745898.

[23] Amanda Shantz \& Jonathan E Booth,Service employees and self-verification: The roles of occupational stigma consciousness and core selfevaluations,in:Human Relations,2014,pp.1439-1465. DOI:10.1177/0018726713519280.

[24] Yang Chen, Yang Fu, Jing Yi \& Tang Mingfeng,How humble leaders improve employee performance: the mediating role of psychological needs satisfaction and the moderating role of work unit structure,in:Nankai Management Review,2018,pp.121-134 +171. DOI:CNKI:SUN:LKGP.0.2018-02-013..

[25] Rong Yan, Yang Baiyin \& Sui Yang,The influence of the sense of power on employee's suggestion behavior-the role of self-verification mechanism,in: Science of Science and Management of Science and Technology,2016,pp.119-129. DOI:CNKI:SUN:KXXG. 0.2016-10-011.

[26] Luo Xingpeng \& Zhang Xiangqian,The cross-level influence of positive leadership on employee's suggestion behavior: a self-verification 
perspective.,in:Forecast,2018,pp.7-14.

DOI:CNKI:SUN:YUCE.0.2018-03-002.

[27] Wang Qingjin, Wei Yufeng \& Li Xianglong,The impact of workplace exclusion on employee innovation behavior: the dual mediating role of organizational commitment and organizational identity,in:Technological progress and countermeasures,2020,pp.134-141. DOI:.

[28] W. B.Swann, Self-verification theory,in P. Van Lang, A. Kruglanski, \& E. T. Higgins (Eds.), Handbook of Theories of Social Psychology ,2002,London.

[29] Hou Xuanfang \& Lu Fucai,The influence of the new generation of work values and intrinsic motivation on work performance-the moderating effect of organizational culture,in:Management Review,2018,pp.157-168.

DOI:10.14120/j.cnki.cn11- 5057/f.2018.04.014.

[30] Wang Hongyu, Wan Pengyu \& Zhang Zhenduo,A sense of overqualification, proof of goal orientation and deviant innovation: a perspective of future attention,in:Business Economics and Management 2020,pp. 45-55. DOI: 10.14134/j.cnki.cn33- 1336/f.2020.02.004. 